\title{
Innovation and challenges in funding rapid research responses to emerging infectious diseases: Lessons learned from the outbreak of severe acute respiratory syndrome
}

\author{
Bhagirath Singh $\mathrm{PhD}$
}

\begin{abstract}
B Singh. Innovation and challenges in funding rapid research responses to emerging infectious diseases: Lessons learned from the outbreak of severe acute respiratory syndrome. Can J Infect Dis Med Microbiol 2004:15(3):167-170

Although the local public health response to the severe acute respiratory syndrome outbreak in Canada was critical to the diagnosis, management and treatment of patients, such a rapid research response required a national effort to engage the research and stakeholder communities. The Canadian research effort, coordinated through the Institute of Infection and Immunity of the Canadian Institutes of Health Research and the Michael Smith Foundation for Health Research, has provided insight into the mechanisms required to ensure the rapid development of strategical initiatives in response to emerging infectious diseases. It has also provided a rational basis to set up a national network to be engaged if needed in the future.
\end{abstract}

Key Words: Emerging infectious diseases; Rapid research response, Research funding; SARS; Severe acute respiratory syndrome

\author{
L'innovation et les défis dans le financement de \\ réponses rapides à des maladies infectieuses \\ émergentes par la recherche : Des leçons \\ apprises grâce à la flambée du syndrome \\ respiratoire aigu sévère
}

La réponse locale de la santé publique à la flambée du syndrome respiratoire aigu sévère au Canada a été essentielle au diagnostic, à la prise en charge et au traitement des patients, mais une réponse si rapide par la recherche a exigé un effort national afin d'engager les collectivités de la recherche et des intervenants. L'effort canadien de la recherche, coordonné par L'Institut des maladies infectieuses et immunitaires des Instituts de recherche en santé du Canada et la Michael Smith Foundation for Health Research, a donné un aperçu des mécanismes nécessaires pour garantir l'élaboration rapide d'initiatives stratégiques en réaction à des maladies infectieuses émergentes. Il a également fourni un fondement rationnel pour mettre sur pied un réseau national qui pourra être mis en branle à l'avenir, au besoin.
A s one of the world's epicentres for the severe acute respiratory syndrome (SARS) outbreak, the Toronto medical community provided scientific evidence and hands-on experience, making Canadian research key in the battle against SARS (1). Canadian scientists across the country took responsibility for fighting the disease, and a team of 58 Canadian researchers was first to publish the genome sequence of the human coronavirus believed to cause SARS (2). This was accomplished using the SARS virus isolated from a patient in Toronto, Ontario and sequenced in Vancouver, British Columbia at the Genome Sciences Centre of the British Columbia Cancer Agency with the help of British Columbia Centre for Disease Control and Health Canada's National Microbiology Laboratory in Winnipeg, Manitoba. Just four years ago the Canadian Institutes of Health Research (CIHR) was created as Canada's premier health research agency with a mandate to create and translate knowledge into improved health for Canadians and a strengthened health care system. In the early days of Canada's SARS outbreak, the CIHR Institute of Infection and Immunity (III) became the testing ground allowing CIHR to rapidly develop the kind of research program that is critical to the understanding and control of new infectious diseases such as SARS. One of the goals of CIHR is to have the capability of responding to the health challenges that affect Canadians with appropriate and timely research programs.

\section{MODELS OF RESEARCH RESPONSE}

On April 10, 2003, within days of the World Health Organization's (WHO) global alert on SARS, III took the first step towards launching a long-term CIHR research strategy on emerging infectious diseases. III launched a request for proposals (RFP) for research into the causes and consequences of SARS, creating the early momentum for SARS research in Canada. A teleconference of concerned stakeholders on April 4, 2003 was the starting point for this RFP. The research community in Canada expressed a strong interest in contributing to SARS research. Within two weeks of the call, 18 research teams across Canada had assembled and submitted proposals. Within 10 days, a rapid peer review had been conducted and four applications were approved (Table 1). The major focus of the funded projects was to develop new diagnostic tools,

Institute of Infection and Immunity, Canadian Institutes of Health Research; Department of Microbiology and Immunology, University of Western Ontario, London, Ontario

Correspondence and reprints: Dr Bhagirath Singh, CIHR Institute of Infection $\mathcal{E}$ Immunity, Suite 214, Siebens-Drake Research Institute Building,

The University of Western Ontario, London, Ontario N6G 2V4. Telephone 519-661-3228, fax 519-661-4226, e-mail bsingh@uwo.ca Received and accepted for publication May 10, 2004 
TABLE 1

Successful teams in the request for proposals for research investigating the causes and consequences of severe acute respiratory syndrome (SARS)

\begin{tabular}{lll}
\hline Principal investigator & Research organization & Research focus \\
\hline Mark Loeb & McMaster University, Hamilton, Ontario & Toward an understanding of SARS: \\
Tanuta Skowronski & TC Centre for Disease Control, & SARS: A scientific collaborative to support public \\
University of British Columbia,Vancouver, British Columbia & health response through vaccination & Molecular markers of immunity and outcome for SARS \\
Michel Bergeron & $\begin{array}{c}\text { Samuel Lunenfeld Research Institute, } \\
\text { University of Toronto, Toronto, Ontario }\end{array}$ & The development of a rapid multiplex SARS assay \\
\hline
\end{tabular}

collect and analyze patient samples, investigate immune responses to the SARS virus in patients and examine the mode of disease transmission. Designing the appropriate research questions and securing adequate funds to launch the RFP within days of the disease outbreak posed two critical challenges for III. Firstly, within traditional granting agencies, funding is not available to launch such emergency research programs. Secondly, delays in securing funding, concerns about the appropriate research questions, the capacity of the research community and delays in the peer review process normally hamper efforts to launch rapid research responses to emerging infectious diseases. However, III took the nontraditional route of committing $\$ 250,000$ from the institute's operating funds, administered through The University of Western Ontario, to launch the program. Discussions with potential partners revealed a strong interest among provincial government departments, volunteer sector agencies and medical research organizations to join with III to support SARS research. Through partnerships, III was able to increase the total funds available for this RFP to $\$ 1.7$ million. The funding partners included the Ontario Research and Development Challenge Fund, the Canadian Network for Vaccines and Immunotherapeutics - a Network of Centres of Excellence (NCE), Le Fonds de la recherche en santé du Québec, and Health Canada. Thus, a new model of funding and a mechanism for engaging the research community for public health emergencies was established. Within three weeks of the launch of our RFP, additional funding complemented our efforts. The Michael Smith Foundation for Health Research (MSFHR) received $\$ 2.6$ million from the government of British Columbia to fund a SARS Accelerated Vaccine Initiative (SAVI). SAVI, headed by Dr Brett Finlay from the University of British Columbia, recruited several laboratories across Canada to undertake a fast-paced vaccine development initiative. This allowed for rapid mobilization of research efforts focused on vaccine development. Two NCEs, namely the Protein Engineering Network of Centres of Excellence (PENCE) and the Mathematics of Information Technology and Complex Systems (MITACS), also committed small amounts of funding for SARS research. The PENCE program was geared to structural and functional studies on SARS viral proteins, and the MITACS effort was focused on mathematical modeling of the SARS outbreak. A great deal has been learned about SARS, but the impact of the disease on the general population beyond the clinical and biomedical concerns clearly justifies the need to continue research at the social and public health levels. Therefore, the CIHR Institutes of Population and Public Health, Health Services and Policy Research, Circulatory and Respiratory Health, and Infection and Immunity, in partnership with the Canadian Lung Association, jointly launched a Request for Applications (RFA) entitled Public Health and Health Care System Preparedness and Response to Severe Acute Respiratory Syndrome (SARS): Evaluation and Lessons Learned. An additional $\$ 1.7$ million has been committed to this RFA to fund grants over a three-year period (Table 2). Development and delivery of this RFA was compressed compared with the standard process, but still required significantly more time than the mechanism used by III and MSFHR. CIHR will continue to refine mechanisms that allow a rapid research response to emerging challenges.

These efforts have been enhanced by the recent announcement by the federal government of the launch of a new Canadian Public Health Agency as recommended late last year by the SARS and Public Health review committee chaired by Dr David Naylor, Dean of Medicine at the University of Toronto. It is expected that this new agency will consider the experience gained by III and MSFHR in its work.

\section{CANADIAN SARS RESEARCH CONSORTIUM}

Because research must be backed by investment and collaboration among partners, the Canadian SARS Research Consortium (CSRC) was launched in June 2003. The CSRC concentrates on identifying gaps and coordinating the research effort, and is based on a noncompetitive approach to addressing highly relevant SARS research issues (Table 3). It functions as a forward-looking body dedicated to maximizing the impact of Canada's resources for SARS research by developing and sustaining a national research agenda and interfacing with the international efforts. Under the umbrella of the CSRC, results of the clinical trial on interferon-alpha therapy of SARS patients have been reported (8) and three potential candidate vaccines have been developed for animal testing (9). The CSRC is currently developing an inventory of SARS research reagents and patient samples in Canada. The CSRC has mobilized and streamlined the Canadian SARS research effort by bringing together funding partners, eliminating duplication and developing more cooperative interaction between different research groups. The formation of the CSRC provides a preliminary infrastructure which could serve as a model for 
TABLE 2

Successful grants from request for applications entitled public health and health care system preparedness and response to severe acute respiratory syndrome (SARS): Evaluation and lessons learned

\begin{tabular}{|c|c|c|}
\hline Principal investigator & Research organization & Research focus \\
\hline T Caulfield & University of Alberta, Edmonton, Alberta, & Legal foundations for national disease control and surveillance agency \\
\hline SW Hwang & $\begin{array}{l}\text { St Michael's Hospital, University of Toronto, } \\
\text { Toronto, Ontario }\end{array}$ & Effect of the Ontario SARS outbreak on population mortality \\
\hline K Khan & $\begin{array}{l}\text { St Michael's Hospital, University of Toronto, } \\
\text { Toronto, Ontario }\end{array}$ & $\begin{array}{l}\text { Optimizing clinical and public health management of influenza-like } \\
\text { illnesses of undetermined etiology in a world changed by SARS }\end{array}$ \\
\hline RG Maunder & $\begin{array}{l}\text { Mount Sinai Hospital, University of Toronto, } \\
\text { Toronto, Ontario }\end{array}$ & $\begin{array}{l}\text { Psychological and occupational impact of the SARS outbreak on } \\
\text { health care workers }\end{array}$ \\
\hline N Mittman & $\begin{array}{l}\text { Sunnybrook and Women's College Health } \\
\text { Sciences Centre, University of Toronto } \\
\text { Toronto, Ontario }\end{array}$ & $\begin{array}{l}\text { Economic evaluation of direct medical and nonmedical costs } \\
\text { associated with the SARS outbreak }\end{array}$ \\
\hline DB Nicholas & $\begin{array}{l}\text { Hospital for Sick Children, University of Toronto } \\
\text { Toronto, Ontario }\end{array}$ & $\begin{array}{l}\text { Exploring the psychosocial and health service consequences of SARS on } \\
\text { children and their families: Lessons learned for pediatric health care } \\
\text { practice and policy }\end{array}$ \\
\hline B Pourbohloul & $\begin{array}{l}\text { University of British Columbia, } \\
\text { Vancouver, British Columbia }\end{array}$ & $\begin{array}{l}\text { The spread and evolution of SARS coronaviruses through contact } \\
\text { networks: Prediction, recognition and control }\end{array}$ \\
\hline MJ Schull & $\begin{array}{l}\text { Sunnybrook and Women's College Health } \\
\text { Sciences Centre, University of Toronto, } \\
\text { Toronto, Ontario }\end{array}$ & $\begin{array}{l}\text { Determining the population health impact of the health care system } \\
\text { response to SARS outbreak }\end{array}$ \\
\hline RE Upshur & $\begin{array}{l}\text { Sunnybrook and Women's College Health } \\
\text { Sciences Centre, University of Toronto } \\
\text { Toronto, Ontario }\end{array}$ & $\begin{array}{l}\text { Ethical challenges in the preparedness and response for SARS: } \\
\text { An interdisciplinary research study }\end{array}$ \\
\hline A Yassi & $\begin{array}{l}\text { University of British Columbia, } \\
\text { Vancouver, British Columbia }\end{array}$ & $\begin{array}{l}\text { Barriers and facilitators to implementing protective measures against } \\
\text { SARS for health care workers: A collaborative interdisciplinary study }\end{array}$ \\
\hline
\end{tabular}

supporting research responses to outbreaks of other infectious diseases in Canada.

The CSRC is comprised of an impressive and dedicated group of partners and scientists. The sponsoring members include CIHR and several of its institutes, Health Canada, provincial health research agencies (MSFHR in British Columbia, Ontario Research and Development Challenge Fund in Ontario and Le Fonds de la recherche en santé du Québec in Quebec), three NCEs (PENCE, Canadian Network for Vaccines and Immunotherapeutics and MITACS), the private sector (GlaxoSmithKline and Aventis Pasteur), and a nonprofit organization (the Canadian Lung Association). The CSRC Scientific Advisory Committee is cochaired by Dr Don Low, chief microbiologist at Mount Sinai Hospital in Toronto and a key medical authority managing Toronto's SARS outbreak, and Dr Brett Finlay, professor in the University of British Columbia's Biotechnology Laboratory and head of SAVI.

\section{THE FUTURE}

The research response to SARS highlights recent provincial and federal investments in health research as contributors to CIHR's ability to quickly develop SARS initiatives to address emerging infectious diseases. SARS has created a demand for research funding around the world. As a federal health research funding agency with a $\$ 662$ million budget - a fraction of the size of that of the United States National Institutes of Health - we know that our success also depends on the phenomenal commitment, vision, flexibility and support of our partners. The investments made by our partners and by the federal government in building infrastructure such as the Canada Foundation for Innovation, Genome Canada, the Canada Research Chairs program and CIHR itself, have certainly contributed to the initiatives in place to block further tolls in lives, well-being and economical impacts because of SARS, and to learn from the disease to prepare for future infectious diseases. With only extramural programs developed and championed by its 13 institutes, CIHR was created to be responsive to the health needs of Canadians. The III's effort to implement this vision through the development of a creative SARS research agenda is an indicator of the success of the CIHR 'virtual' structure linking researchers across the country, and the CIHR emphasis on partnership, which extends its impact while building collaboration among those who support health research leading to better health and health care in this country. SARS has captured the attention and imagination of the world (7). Yet SARS is still thought to be a 'dry run' for an expected influenza pandemic (5). The challenge will be to see if the teamwork that has characterized Canada's response to SARS can be sustained for emerging infectious diseases that are not yet in the public arena. This brand of teamwork must also be taken up internationally, as only a cohesive international response will have an impact against newly emerging diseases (6). The tremendous impact of global cooperation, such as that of the WHO's 13-member collaborative multicentre research project on SARS diagnosis, was seen in the swift identification of the coronavirus and its containment. Such international linkages must be strengthened, and the research 
TABLE 3

Canadian SARS Research Consortium: Research goals and theme leaders

\begin{tabular}{|c|c|}
\hline Goals & Theme leader and institution \\
\hline Reliable diagnostic assays for SARS & $\begin{array}{l}\text { Frank Plummer, National Microbiology Laboratory, Health Canada, } \\
\text { Winnipeg, Manitoba }\end{array}$ \\
\hline New or existing antivirals for SARS therapy & Lorne Tyrrell, University of Alberta, Edmonton, Alberta \\
\hline Animal model for SARS and development of an anti-SARS vaccine & $\begin{array}{l}\text { Lorne Babiuk, Vaccine \& Infectious Disease Organization, } \\
\text { University of Saskatchewan, Saskatoon, Saskatchewan }\end{array}$ \\
\hline Epidemiological modelling of the disease outbreak & Mark Loeb, McMaster University, Hamilton, Ontario \\
\hline Examine public health impacts and develop strategies for future actions & $\begin{array}{l}\text { Paul Gully, Population and Public Health Branch, Health Canada, } \\
\text { Ottawa, Ontario }\end{array}$ \\
\hline
\end{tabular}

SARS Severe acute respiratory syndrome

commitment by Canadian scientists will ensure that Canada remains an integral part of the international effort. Recently, WHO has undertaken the development of rapid response capacity to infectious diseases by developing a global network of laboratories and other organizations (10). As many of the goals of the CSRC, outlined in Table 3, have been met (7), we are creating a forward-looking Canadian Rapid Research Team of relevant partners and stakeholders. This will ensure that

\section{REFERENCES}

1. Poutanen SM, Low DE, Henry B, et al. Identification of severe acute respiratory syndrome in Canada. N Engl J Med 2003;348:1995-2005.

2. Marra MA, Jones SJ, Astell CR, et al. The Genome sequence of the SARS-associated coronavirus. Science 2003;300:1399-404.

3. Pearson H, Clarke T, Abbott A, Knight J, Cyranoski D. SARS: What have we learned? Nature 2003;424:121-6.

4. Bernstein A. Get ready for the next SARS: More epidemics are coming, and understanding them is our best defence. The Globe and Mail (Toronto) 2003 June 19, Section A:15.

5. Zambon M, Nicholson KG. Sudden acute respiratory syndrome. BMJ 2003;326:669-70.
Canada develops its own capacity and remains an integral part of the international effort to prepare for future research challenges in emerging infectious diseases.

ACKNOWLEDGEMENTS: The author is grateful to Dr Alan Bernstein for timely advice, Tess Laidlaw and Carol Richardson for help in the preparation of this article and the Canadian Institutes of Health Research for infrastructure support.

6. Science. Special online collection of SARS research articles: The SARS epidemic. <www.sciencemag.org/feature/data/sars/> (Version current at May 17, 2004)

7. La Montagne JR, Simonsen L, Taylor RJ, Turnbull J, SARS Research Working Group Co-Chairs. Severe acute respiratory syndrome: Developing a research response. J Infect Dis 2004;189:634-41.

8. Loutfy MR, Blatt LM, Siminovitch KA, et al. Interferon alfacon-1 plus corticosteroids in severe acute respiratory syndrome: A preliminary study. JAMA 2003;290:3222-8.

9. Marshall E, Enserink M. Medicine. Caution urged on SARS vaccines. Science 2004;303:944-6.

10. Enserink M. Emerging infectious diseases: A global fire brigade responds to disease outbreaks. Science 2004;303:1605. 


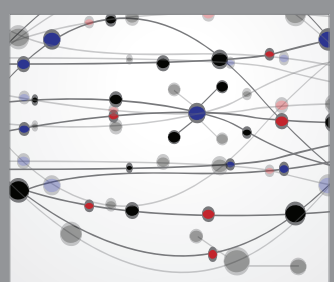

The Scientific World Journal
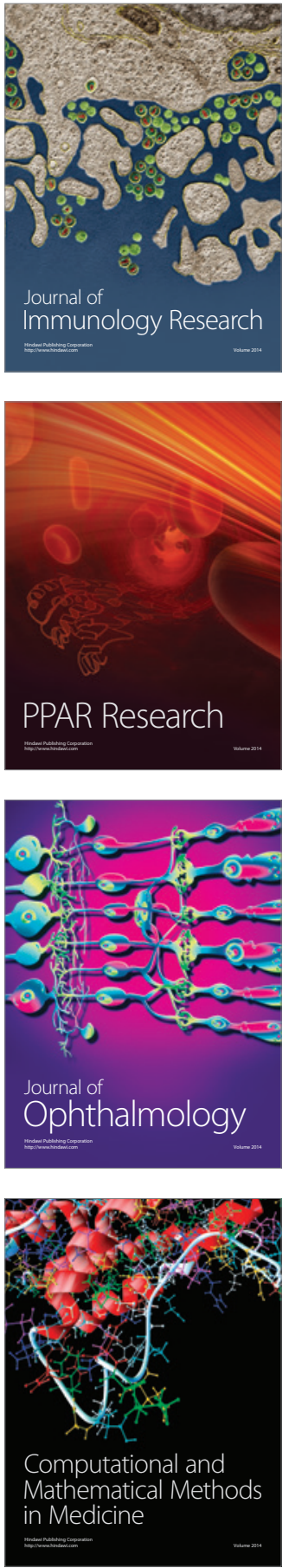

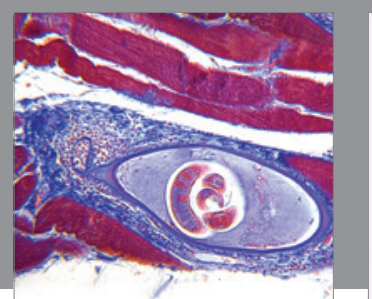

Gastroenterology Research and Practice

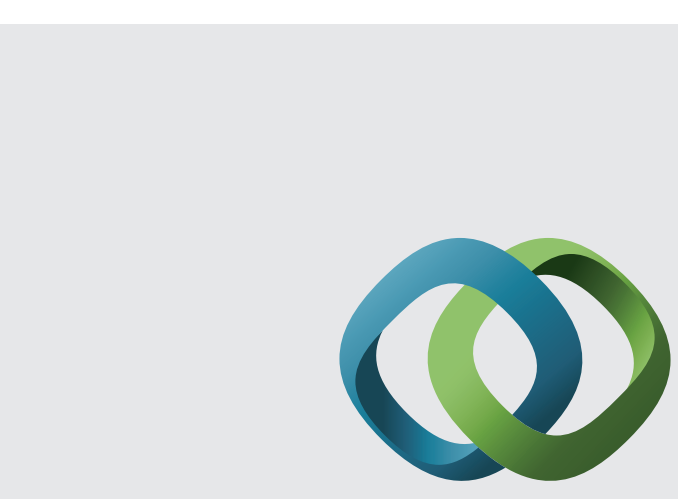

\section{Hindawi}

Submit your manuscripts at

http://www.hindawi.com
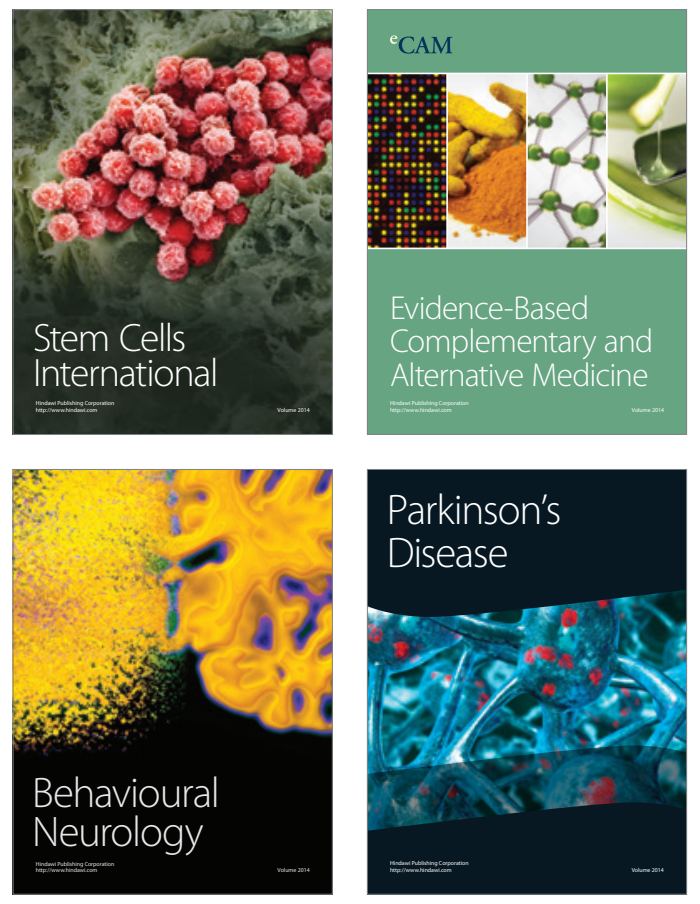
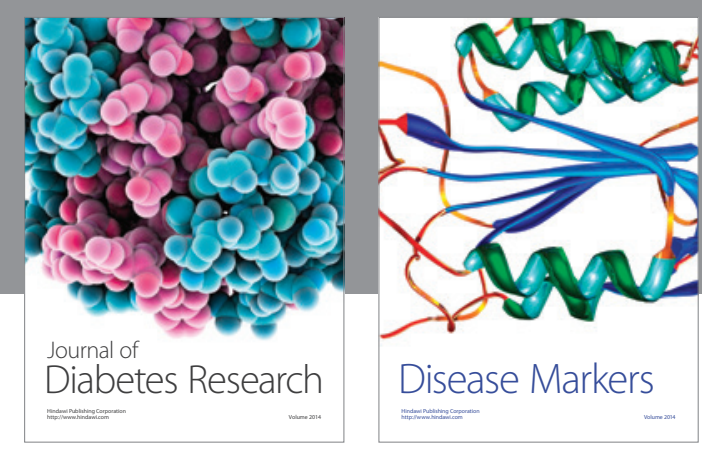

Disease Markers
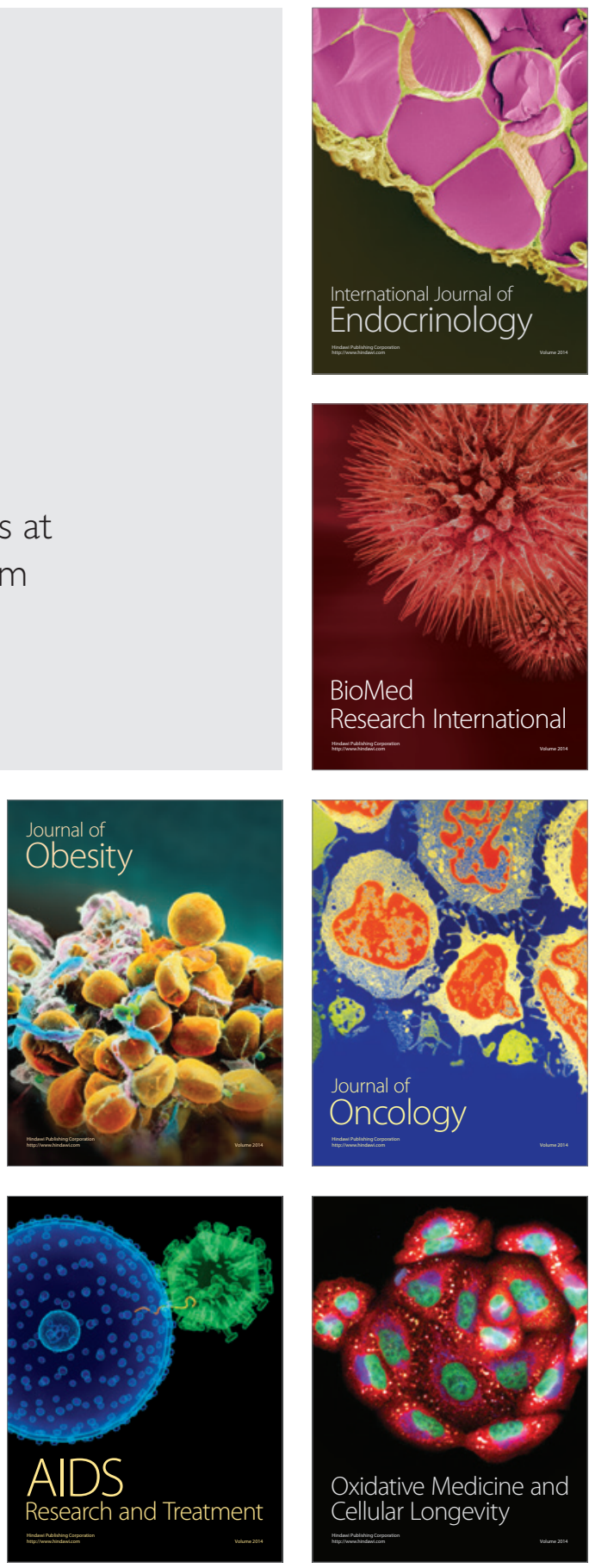